\title{
Successful intraosseous adenosine administration in a newborn infant with supraventricular tachycardia
}

\author{
İlknur Fidanc1 ${ }^{1 \oplus}$, Okşan Derinöz Güleryüz ${ }^{1 \oplus}$, Ömer Doğan Yenice ${ }^{2 \odot}$ \\ ${ }^{1}$ Division of Pediatric Emergency Medicine, ${ }^{2}$ Department of Pediatrics, Gazi University Faculty of Medicine, Ankara, Turkey.
}

\begin{abstract}
Background. Supraventricular tachycardia (SVT) is the most common type of tachycardia in childhood. The incidence is $1-4 / 1000$ in childhood and 0.6/1000 in newborns.

Case. Here we report a 28-day-old male newborn who was diagnosed SVT, admitted to the Pediatric Emergency Department after restlessness that had started three hours before admission and measurement of the heart rate was above 250 beats/min.

Conclusions. This case is presented in order to emphasize that SVT is rare in the neonatal period and SVT is successfully terminated with the administration of intraosseous adenosine.
\end{abstract}

Key words: adenosine, newborn, intraosseous, adenosine, supraventricular tachycardia.

Supraventricular tachycardia (SVT) is the most common symptomatic tachycardia which requires medical treatment in childhood. ${ }^{1}$ SVT attacks occur in 1-4 of every 1000 children. Its incidence in newborn infants is much lower and it has been reported to occur in only 6 out of every $10.000 .^{2}$

Clinical findings in SVT may differ depending on the age of the child and the duration of the SVT. While children can be admitted with the feeling of palpitations, infants can be admitted with pallor, restlessness, lack of nutrition, cyanosis and tachypnea. ${ }^{3}$ In SVT of infants, the first 12-24 hours are well tolerated, symptoms may be mild and tachycardia may not be recognized for a long time. Therefore, babies may present with heart failure (tachypnea, decreased weight gain, fatigue while feeding, perfusion disorder). ${ }^{4}$

The goal of acute treatment of SVT is to immediately convert the rhythm to sinus

$凶$ İlknur Fidanc1

drilknuraksoy@hotmail.com

Received 27th April 2020, revised 12th June 2020, accepted 28th July 2020. rhythm and prevent the rhythm from recurring. Vagal maneuvers, chemical cardioversion (i.e. adenosine) and synchronized cardioversion can be used in the treatment. The choice of treatment depends on the patient's hemodynamic and clinical status. Vagal maneuvers and adenosine are recommended as the first-line treatment method in infants with stable hemodynamic status. $^{5}$ Pediatric Advanced Life Support (PALS) guidelines stated that adenosine can be administered intravenously (IV) or intraosseous (IO) in the treatment of SVT. ${ }^{6}$ However, the IO administration of adenosine, which is often administered IV, is controversial. ${ }^{7}$ This case is presented to emphasize that SVT is rare in the neonatal period and SVT has been successfully terminated with IO adenosine administration.

\section{Case Report}

A 28-day-old male newborn who was born at 38 weeks 2 days via C-section, weighed 3450 grams, and was the first born of a 28 -yearold mother was admitted to the Pediatric Emergency Department after restlessness that started three hours before the admission and measurement of the heart rate above 250 beats/ min by the family. It was learned that he was 
admitted to the neonatal intensive care unit due to tachypnea at 13 days of age. Tachycardia was detected on the day of hospitalization and he was diagnosed with SVT. Thus; IV adenosine was administered and the SVT attack terminated so he was discharged with oral propranolol treatment after one week of follow-up. Echocardiography performed at his hospitalization was normal. He was using propranolol from $1.5 \mathrm{mg} / \mathrm{kg}$ with no family history.

His vital signs were as follows: body temperature: $36.4^{\circ} \mathrm{C}$, respiratory rate: $40 / \mathrm{min}$, heart rate: 288 beats/min-rhythmic, systolic blood pressure: $100 \mathrm{mmHg}$, SpO2:100\%. No pathology other than tachycardia was detected on examination. Electrocardiogram findings were narrow QRS waves without $P$ waves (Fig. 1). Therefore, the newborn was diagnosed with SVT. Upon vagal maneuver (ice application to the face) and failure of vascular access (three times), adenosine $(0.1 \mathrm{mg} / \mathrm{kg})$ was administered via EZ-IO ${ }^{\circledast}$ pathway from the left tuberosity tibia medial metaphysis and his pulse was reduced to normal limits immediately (Fig. 2). Posterioranterior lung $\mathrm{X}$-ray imaging was normal.
Laboratory tests revealed: $\mathrm{Hb}: 14.7 \mathrm{~g} / \mathrm{dL}$, Hct: 46.2\%, CK: 463 U / L (0-171U / L), CK-MB (Mass): $12.14 \mathrm{ng} / \mathrm{ml}(3.6-4.8 \mathrm{ng} / \mathrm{ml}) \mathrm{Hs}$ - Troponin T: was $297 \mathrm{ng} / \mathrm{L}$ (0-14 $\mathrm{ng} / \mathrm{L})$. At the 6th hour of the follow-up, the SVT attack repeated, since peripheral vascular access was achieved during this period, adenosine was given IV $(0.1 \mathrm{mg} /$ $\mathrm{kg}$ ) and the attack terminated. The infant was discharged from the emergency room at the $48^{\text {th }}$ hour of his follow-up with oral propranolol and called for a control examination one week later. Permission was obtained from the parents for publication of this case and informed consent was obtained from the family.

\section{Discussion}

Adenosine, which is frequently preferred after vagal maneuver in hemodynamically stable SVT cases can be administered frequently as IV and rarely as IO. ${ }^{6}$

Adenosine is metabolized by the adenosine deaminase (ADA) enzyme in the erythrocyte membrane in 10 seconds. Therefore, in order to terminate the SVT attack, it must be given in an appropriate dose, with a suitable route and

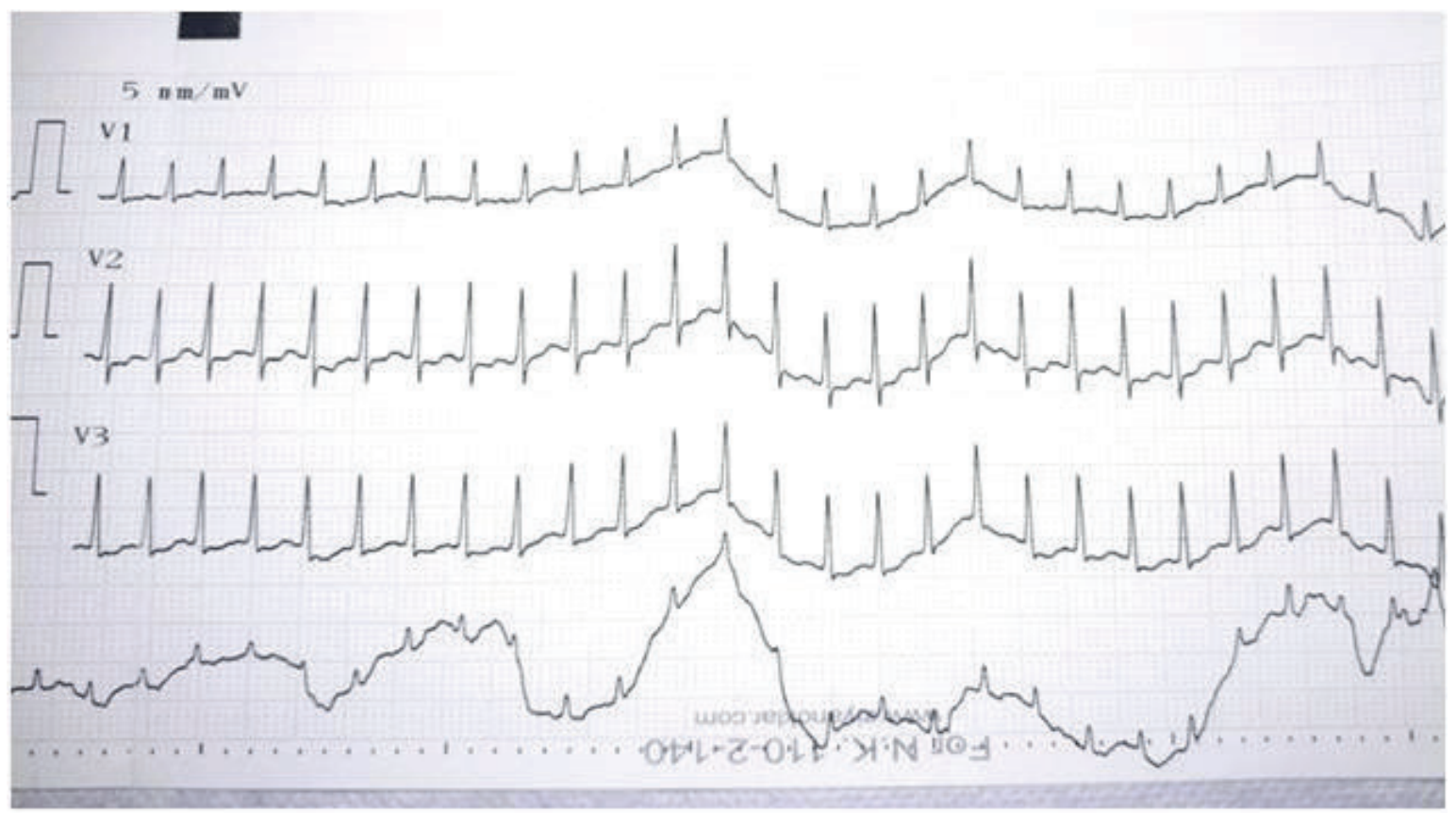

Fig. 1. First ECG of the newborn. Narrow QRS wave tachycardia can be seen. 


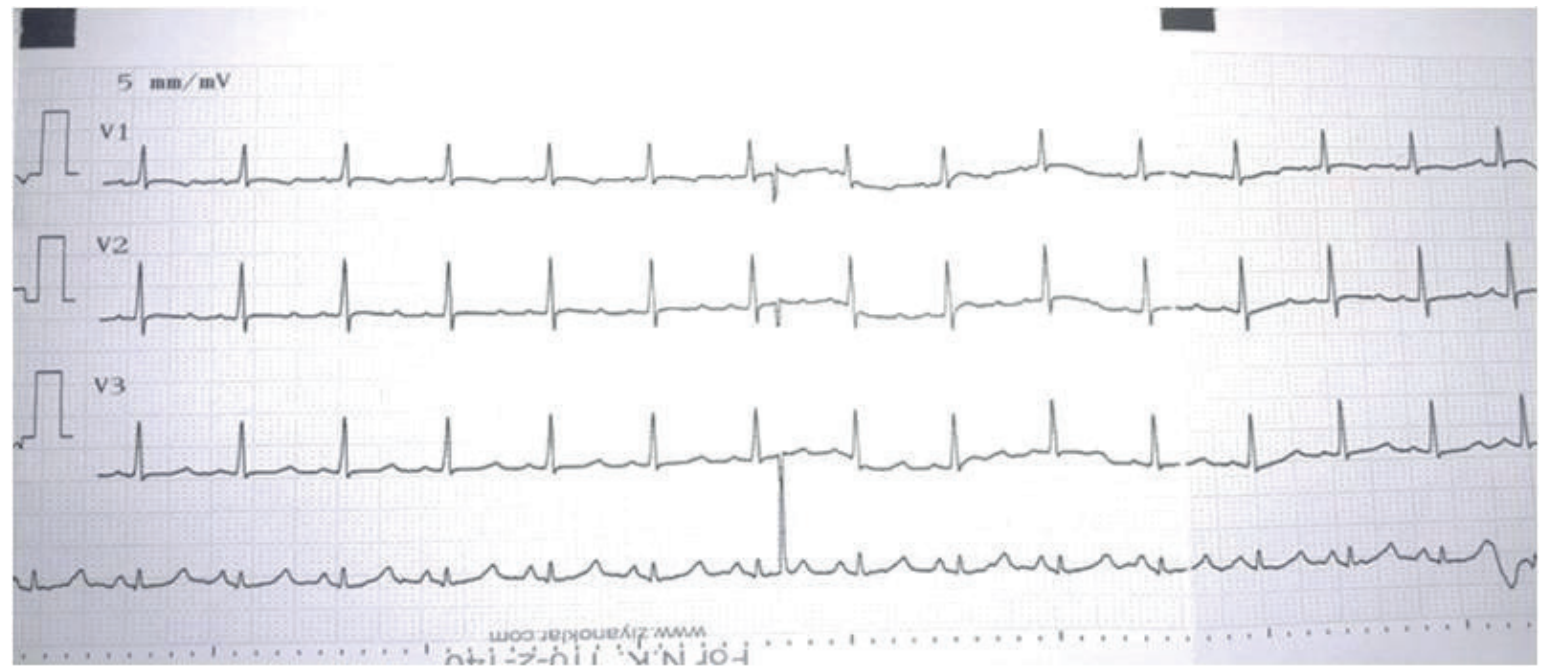

Fig. 2. ECG during IO adenosine administration. Sinus rhythm can be seen.

appropriate method. The recommended dose is $0.1 \mathrm{mg} / \mathrm{kg}$. ${ }^{8}$ It is preferred that the vein to be selected is the largest vein closest to the heart and the application of the flush method is very important when administering adenosine. ${ }^{9,10}$

Adenosine is a purine analog used in SVT since 1980. Adenosine stimulates potassium channels by binding to cardiac receptors and inhibiting calcium flow with G-CAMP-dependent mechanism. It acts via hyperpolarization in cardiac myocytes and slows down the transmission in the atrioventricular node ${ }^{11}$ and usually terminates SVT within 20 seconds, approximately $72-78 \%$ of cases respond to adenosine. $^{12}$

Treatment of SVT is vagal maneuver (ice application to the face, 15-30 second) for hemodynamically stable infants, IV adenosine $(0.1 \mathrm{mg} / \mathrm{kg})$ if the vagal maneuver is not effective. If no response is received within two minutes, IV adenosine $(0.2 \mathrm{mg} / \mathrm{kg})$ is administered for the second time. ${ }^{13}$ When the IV route cannot be opened within one minute the IO route can be opened and adenosine can be administered via the IO route. Antiarrhythmic drugs such as amiodarone and procainamide can be used in adenosine resistant SVT cases. In hemodynamically unstable infants, synchronized cardioversion (0.5- 1 joule $/ \mathrm{kg}$ if no response 2 joule/kg) should be applied. (6). The use of IO amiodarone can also be considered when IO adenosine administration fails, but the studies in the literature are mostly on adult patients. $^{14}$

The intraosseous route was first defined in 1922 and has been used more widely in children since 1980s. It is a good alternative for drug and fluid treatment in critical patients who central and peripheral IV route cannot be achieved. ${ }^{15} \mathrm{IO}$ route should be used in children for three to four hours (maximum 24 hours) and access to the IV route should be obtained as soon as possible to reduce the development of complications related to the IO route. ${ }^{16}$ Proximal tibia, distal tibia, sternum, proximal humerus and iliac wing can be used for the IO route. However, sternum should not be preferred in critical patients who may require cardiac resuscitation. ${ }^{17}$

Several different commercially available IO cannulation devices are available. Manual IO needles, battery powered driver (EZ-IO) and impact-driven devices (Bone injection gun [BIG], FAST) are preferred for IO cannulation. Other types of needles may be used if an IO needle or device is not available; these include bone marrow needles, styletted needles, and spinal needles. The device EZ-IO was approved by the Food and Drug Administration in 2004. The device consists of battery powered driver for insertion with different needle 
length and gauge for placement in children and adults. Studies in animal and human cadavers demonstrated the superiority of the EZ-IO $\AA$ over both, the manual needle and the BIG, regarding successful insertion on the first attempt. ${ }^{18,19}$

There is very little literature on both efficacy and administration related to IO adenosine administration in SVT. The first animal study conducted in 30 new weaning piglets in 1994 aimed to determine the effectiveness of IO adenosine and the therapeutic dosage of IO adenosine compared to the peripheral and central venous route. IO adenosine administration was found to be more effective and the therapeutic dosage range was found to be higher than the central venous route and slightly lower than the peripheral venous route. ${ }^{7}$

To the best of our knowledge, there have only been four infants to undergo the IO adenosine treatment because of SVT in the literature. Two of them were newborns, two of them were infants. ${ }^{20-22}$ While the newborn cases were successfully treated with $0.1 \mathrm{mg} / \mathrm{kg}$ IO adenosine administration; no responses were received from the 2 months old infant with $0.25 \mathrm{mg} / \mathrm{kg}$ dose of IO adenosine and $0.2 \mathrm{mg} /$ $\mathrm{kg}$ dose from 4 months old infant. ${ }^{21}$ Herein we have reported a newborn who experienced the first SVT attack at 13 days of age and the second SVT attack at 28 days of age who successfully responded to $0.1 \mathrm{mg} / \mathrm{kg}$ adenosine administered IO during a SVT attack. The fact that successful IO adenosine cases in the literature are also newborns, suggesting that ADA activity may be lower in newborns compared to older ages. A lower level of ADA activity in newborns may be the reason that adenosine administrated by IO route acts without being metabolized. The reason for the absence of IO adenosine administration in the older age group in the literature may be the fact that the IV route is more easily accessed in older patients.

Although SVT is one of the common causes of tachycardia in childhood, it is a very rare condition in newborns. While the effectiveness of IO adenosine in children is controversial, the literature on this subject is very limited. In our case, IO adenosine was successful in terminating the SVT attack. In the treatment of SVT, it is important to choose the appropriate treatment according to the hemodynamic status of the infant and to use appropriate doses of drugs.

\section{REFERENCES}

1. Richardson C, Silver ES. Management of supraventricular tachycardia in infants. Paediatr Drugs 2017; 19: 539-551.

2. Wu MH, Chen HC, Kao FY, Huang SK. Postnatal cumulative incidence of supraventricular tachycardia in a general pediatric population: a national birth cohort database study. Heart Rhythm 2016; 13: 2070-2075.

3. Spearman AD, Williams P. Supraventricular tachycardia in infancy and childhood. Pediatr Ann 2014; 43: 456-460.

4. Gilljam T, Jaeggi E, Gow RM. Neonatal supraventricular tachycardia: outcomes over a 27year period at a single institution. Acta Paediatr 2008; 97: 1035-1039.

5. BET 2: Campbell M, Buitrago SR. Ice water immersion, other vagal manoeuvres or adenosine for SVT in children. Emerg Med J 2017; 34: 58-60.

6. de Caen AR, Berg MD, Chameides L, et al. Part 12: Pediatric Advanced Life Support: 2015 American Heart Association Guidelines Update for Cardiopulmonary Resuscitation and Emergency Cardiovascular Care. Circulation 2015; 132(18 Suppl 2): S526-S542.

7. Getschman SJ, Dietrich AM, Franklin WH, Allen HD. Intraosseous adenosine. As effective as peripheral or central venous administration. Arch Pediatr Adolesc Med 1994; 148: 616-619.

8. Paul T, Bertram H, Bökenkamp R, Hausdorf G. Supraventricular tachycardia in infants, children and adolescents: diagnosis, and pharmacological and interventional therapy. Paediatr Drugs 2000; 2 : 171-181.

9. Lewis J, Arora G, Tudorascu DL, Hickey RW, Saladino RA, Manole MD. Acute management of refractory and unstable pediatric supraventricular tachycardia. J Pediatr 2017; 181: 177-182.e2.

10. Lerman BB, Markowitz SM, Cheung JW, Liu CF, Thomas G, Ip JE. Supraventricular tachycardia: mechanistic insights deduced from adenosine. Circ Arrhythm Electrophysiol 2018; 11: e006953. 
11. Singh S, McKintosh R. Adenosine. [Updated 2020 Jul 10]. In: StatPearls [Internet]. Treasure Island (FL): StatPearls Publishing. (Available from: https://www. ncbi.nlm.nih.gov/books/NBK519049/)

12. Díaz-Parra S, Sánchez-Yañez P, Zabala-Argüelles $\mathrm{I}$, et al. Use of adenosine in the treatment of supraventricular tachycardia in a pediatric emergency department. Pediatr Emerg Care 2014; 30: 388-393.

13. Quail MA, Till J. Question 3 Does a higher initial dose of adenosine improve cardioversion rates in supraventricular tachycardia? Arch Dis Child 2012; 97: 177-179.

14. Daya MR, Leroux BG, Dorian P, et al; Resuscitation Outcomes Consortium Investigators. Survival after intravenous versus intraosseous amiodarone, lidocaine, or placebo in out-of-hospital shockrefractory cardiac arrest. Circulation 2020; 141: 188198.

15. Luck RP, Haines C, Mull CC. Intraosseous access. J Emerg Med 2010; 39: 468-475.

16. Derinoz O, Keles A. Powered intraosseous device (EZ-IO) for critically ill patients. Indian Pediatr 2013; 50: 689-691.
17. Rosenberg H, Cheung WJ. Intraosseous access. CMAJ 2013; 185: E238.

18. Frascone RJ, Jensen J, Wewerka SS, Salzman JG. Use of the pediatric EZ-IO needle by emergency medical services providers. Pediatr Emerg Care 2009; 25: 329332.

19. Shavit I, Hoffmann Y, Galbraith R, Waisman Y. Comparison of two mechanical intraosseous infusion devices: a pilot, randomized crossover trial. Resuscitation 2009; 80: 1029-1033.

20. Friedman FD. Intraosseous adenosine for the termination of supraventricular tachycardia in an infant. Ann Emerg Med 1996; 28: 356-358.

21. Goodman IS, Lu CJ. Intraosseous infusion is unreliable for adenosine delivery in the treatment of supraventricular tachycardia. Pediatr Emerg Care 2012; 28: 47-48.

22. Helleman K, Kirpalani A, Lim R. A novel method of intraosseous infusion of adenosine for the treatment of supraventricular tachycardia in an infant. Pediatr Emerg Care 2017; 33: 47-48. 